\title{
Solar Heat Integration in Non-Repeatable Time Slices on Daily Basis
}

\author{
*1.Aleksandar Anastasovski \\ ${ }^{1}$ International Balkan University, Skopje, Macedonia
}

\begin{abstract}
Global heating and environmental protection are the main reasons for expanding the use of solar heat in domestic and industrial facilities. The other benefit from this renewable energy source is getting free heat energy. It is quite interesting for industrial processes, but there are some general problems that should be solved, like its periodicity, weather conditions as well as production system heat demands. In this paper was analysed possibilities for scheduling of batches with heat supply from solar heating system. That was done for independent batches that are working on independent lines. They can work at any time of the day independently from each other and as parallel processes. The main problem in scheduling is limited supply of solar heat. By using the data for solar irradiation in the city of Bitola (the place used for calculations) was explained the suggested scheduling procedure and created the schedule of batches dependent to insolation.
\end{abstract}

Key words: Solar heat, independent batches, scheduling, non-repeatability, heat integration.

$\begin{array}{ll}\text { Abbreviations } \\ \text { CIP } & \text { Cleaning in place } \\ \text { GT } & \text { Group Technology } \\ \text { IEA } & \text { International Energy Agency } \\ \mathrm{P} & \text { Pasteurisation } \\ \mathrm{S} & \text { Sterilisation } \\ \mathrm{h} & \text { enthalpy }[\mathrm{kJ}] \\ \mathrm{W} & \text { work }[\mathrm{kW}] \\ \mathrm{c} & \text { heat capacity } \\ \mathrm{m} & \text { mass flow }[\mathrm{kg} / \mathrm{s}] \\ \mathrm{g} & \text { gravity }\left(9.81 \mathrm{~m} / \mathrm{s}^{2}\right) \\ \mathrm{V} & \text { velocity }[\mathrm{m} / \mathrm{s}] \\ \mathrm{z} & \text { high }[\mathrm{m}] \\ \mathrm{Q} & \text { heat load }[\mathrm{kJ}] \\ \mathrm{q} & \text { heat flow }[\mathrm{kW}] \\ \mathrm{s} & \text { start-up time } \\ \mathrm{p} & \text { processing time } \\ \mathrm{M} & \text { makespan }\end{array}$

\section{Introduction}

The solar thermal radiation is very important as free heat energy. It can be used during the daylight. Every point on the earth surface has its own value for solar insolation. It is specific for geo-position

*Corresponding author: Address: International Balkan University, Faculty of Engineering, Department of Industrial management, Skopje, MACEDONIA. E-mail address: AleksandarA@t.mk 


\section{A.ANASTASOVSKI/ ISITES2019 SanliUrfa - Turkey}

and the period of the year. There are many databases that can be used for determination of solar thermal radiation intensity. If the solar radiation is analysed during the day, it can be easily noticed the difference of insolation intensity. Solar thermal radiation is expressed as average daily solar radiation. This means the intensity is the lowest at sunrise and sunset. It has maximal radiation for several hours in the middle of the day. The distribution of solar radiation has the form of a Gaussian curve (Figure 1). The average value of solar radiation (the insolation curve) during the day is the integrated value of solar radiation through the day. Solar radiation can be direct and diffuse. Solar radiation that directly falls on the surface of the collector is direct solar radiation. However, radiation reflected in the atmosphere or objects in the environment is called diffuse radiation. The sum of both types of solar radiation makes the total solar radiation that generates a hot medium in the collector or concentrator.

There are many methods for optimal scheduling of batch processes. Majozi and his collaborators are maybe the most dedicated to solving problems in heat integration of batch processes. Lee et al. [1] suggested heat integration with intermittently available continuous streams that could be found in multipurpose batch plants. Majozi presented a heat integration model for multipurpose batch plants based on the continuous-time scheduling framework. The result showed smaller problems compared to the discrete-time formulation in large-scale problems. They improved the profit of an agrochemical industrial case study for $18.5 \%$. The direct heat integration model was extended to incorporate heat storage for more flexible schedules and utility savings. Costa made [2] a review of optimisation methods used in scheduling of batch processes. He shows methods related to mathematical programming as optimisation methods. But also he proposed hybrid genetic algorithm for solving of such issue of batch scheduling. Moniz et al. [3] used Mixed Integer Linear Programming formulation of the problem for scheduling of processes with redesign of equipment based on Resource-Task Network representation. Ning and You [4] proposed data-driven multistage adaptive robust optimisation for scheduling of batch processes. They used different robust loss function as Huber loss function and Hampel loss function.

The International Energy Agency - IEA team coordinated by Bettina Muster prepared integration guidelines for solar integration in industrial processes [5]. They determined the possible points for solar heat integration. Those points are water preheating for steam boilers; additional heating of Heat Supply Storage and Heat Supply Network (Integration on Supply Level); as well as additional heating of Process Heat Storage, heating of processes and vessels, and heating of the process heating medium (Integration Process Level). Muster-Slawitsch et al. came up with the Green Brewery concept to demonstrate the potential for reducing thermal energy consumption in breweries. Three detailed case studies have been performed. The "Green Brewery" concept has shown a saving potential of over 5,000 ton/year fossil $\mathrm{CO}_{2}$ emissions from thermal energy supply for the three breweries that were closely considered.

There are very small number of articles that include solar heat integration and scheduling of batches. Some authors showed and reviewed different models of solar radiation that can be used in modelling of production systems. Maleki et al. [6] made a review of different models determined for solar radiation on inclined surfaces.

This paper proposes new approach for solving problems of independent batches on a daily basis. The case study used for explanation of the new methodology is theoretical. It is explained in the 
part of materials and methods. There is clarified the main issue that can be found in workshops or some food production facilities that contain independent batch processes that can be done at any time of the day. But the main limitation in this case is solar thermal energy and its maximal use.

\section{Materials and methodology}

The use of solar heat has an impact to the industrial plants. In case when production plant is only supplied with solar heat through a static collector, it would not receive the appropriate heat if it occurs at the beginning or at the end of the day. This can be specific for systems that contain independent batch processes which can be distributed at any time during the day.

\subsection{Scheduling and problem statement}

Some factories and workshops in which the batches are independent, could be created different recipes for different days. The schedule of these batches depends on customer requirements and the production system characteristics. The production batches are not repeating in the same order as cycles. The combination of machines and process streams used in the same time (in the same Time Slice) are not giving the same recipes. They form non-repeatable time slices. This is a case in the food industry. Using of solar heat is getting free energy for the facilities and improves the profit of company.

Batch processes can be defined as semi-continuous. They are classified as multi-product and multipurpose. Multi-product batch processes produce different products within the same processing network. Multipurpose batch processes, products are manufactured in different processing networks. there could have more than one way to manufacture the same product. According to Operational Research literature, multi-product batch processes are called flow-shops. Multipurpose processes depend on job size, jobs are linked to each other throw material balances and intermediate storage requirements. [8]. Operational research classifies them as job shop.

Batch is a collection of jobs that take place in one or a set of machines [9]. This is so-called Group Technology (GT). All those processes or jobs that create the batch have start-up time and processing time. It is defined with Equation (1). The make span of all batches $\mathrm{M}$ is the sum of all start-ups $\mathrm{s}$ and processing times $\mathrm{p}$ of all batches. The minimisation of make span depends on the created schedule. [10] [11].

$$
M=\sum_{i=1}^{n} s_{i}+p_{i}
$$

The independent batches look like a case with parallel machines. The theory of scheduling gives instructions for minimisation of make-span (Equation (2)). This formula can be used for minimisation of make span of batches $($ jobs $-\mathrm{j}$ ) on different process lines (machines $-\mathrm{m})$.

$$
M=\max \left[\sum_{j=1}^{n} p_{j} / m, \max _{j}\left\{p_{j}\right\}\right]
$$

But the batches are dependent on resources. In case that all resources are available except the solar heat, the whole scheduling depends on the solar heat supply.

The case study for explanation of new way of scheduling of independent batches on independent 
process lines is a dairy factory. There are many production processes that are done independently as batch processes for pasteurisation and sterilisation of milk, production of yogurt, cheese and other dairy products. All these processes require heat during the whole process or in parts of processes. Pasteurisation is the process of heating milk to temperature of $60^{\circ} \mathrm{C}$ or above. Sterilisation of milk is heating of milk to the temperature of $121{ }^{\circ} \mathrm{C}$ for a few seconds. Production of yogurt is related to heating of milk to temperatures between $65-75^{\circ} \mathrm{C}$ for fermentation with lacto-bacterias. In time of fermentation must be kept the constant temperature. The prerequirement in those processes is cleaning in place (CIP). It must be done before starting of processes. That is batch start-up. If the time period is longer, then must have CIP at the end of the batch. All these processes are independent batches that require heat. The heat is determined with material and energy balances made for these processes. The whole system is analysed and simulated based on material balance (Eq.(3)) and heat balance (Eq.(4)). This is done for every process stream $j$ that exist in the system $i$.

$$
\begin{gathered}
\sum_{j \in I N(i, j)} \dot{m}_{j}-\sum_{j \in O U T(i, j)} \dot{m}_{j}=0 \quad \forall \mathrm{i} \in \mathrm{I} \\
\sum_{j \in I N(i, j)} \dot{m}_{j}\left(h_{j}+\frac{V_{j}^{2}}{2}+g \cdot z_{j}\right)-\sum_{j \in O U T(i, j)} \dot{m}_{j}\left(h_{j}+\frac{V_{j}^{2}}{2}+g \cdot z_{j}\right)-\dot{W}_{i}+\dot{Q}_{i}=0
\end{gathered}
$$

Where parameters have the following values: $\dot{W}_{i}=0, \dot{Q}_{i}=0, \quad V_{j}^{2}=0, \quad z_{j}=0$, $\forall i \in$ process system. In Table 1 are given batch processes with their characteristics.

Table 1. Characteristics of batches in the example case

\begin{tabular}{lccccc}
\hline Batch process & $\begin{array}{c}\text { Batch capacity } \\
{\left[\mathrm{m}^{3}\right]}\end{array}$ & $\begin{array}{c}\text { Material flow } \\
{\left[\mathrm{m}^{3} / \mathrm{h}\right]}\end{array}$ & $\begin{array}{c}\text { Process time } \\
{[\text { hours }]}\end{array}$ & $\begin{array}{c}\text { Required heat } \\
{[\mathrm{kJ}]}\end{array}$ & $\begin{array}{c}\text { Heat flow } \\
{[\mathrm{kW}]}\end{array}$ \\
\hline CIP & 15 & - & Available heat & $1,884,150$ & 523.4 \\
$\begin{array}{l}\text { CIP (preheating in time } \\
\text { of cleaning) }\end{array}$ & 2.5 & 10 & 0.25 & 314,025 & 145 \\
Pasteurisation 1 (P1) & 5 & 10 & 0.5 & $1,055,600$ & 586.5 \\
Pasteurisation 2 (P2) & 15 & 10 & 1.5 & $3,166,800$ & 586.5 \\
Pasteurisation 3 (P3) & 10 & 10 & 1 & $2,111,200$ & 586.5 \\
Sterilisation (S1) & 10 & 20 & 0.5 & 2299700 & $1,277.6$ \\
\hline
\end{tabular}

The batch processes given in Table 1 need to be scheduled for maximal usage of solar heating system without heat storage. As it was mentioned, the limitation is solar heat supply to the collector surface (adsorption area). So, the next step is the extraction of data for solar radiation at certain days. 


\subsection{Solar daily irradiation}

Daily solar radiation is different for every day during the year. In the summer solstice, the length of the day is 15 hours and the night is shortest with 9 hours. Opposite, winter solstice has the shortest day with duration of 9 hours. These two days are extremes, but the length of insolation, insolation angle and naturally the weather conditions are very important in solar heat supply. There are many web databases made by various institutions that have free access to get data about solar irradiation in certain geo-position for the whole year measured by days, hours or smaller time periods as 30 minutes, 15 minutes etc. The analysed problem is placed in the city of Bitola. The solar radiation data for Bitola are found in HelioClim web bases [12]. The extracted data are shown in Figure 1. There can be seen four curves that looks like Gaussian functions. Practically, they are curves of solar heat distribution at the summer solstice, equinoxes and winter solstice. The time period is taken to be 15 minutes. So, there is shown the heat that arrives every 15 minutes to the 1 $\mathrm{m}^{2}$ of the earth surface. The whole solar heat distribution to the surface is sequenced to 15 minutes. The Figure 1 shows the ideal conditions. If there is bad weather, the heat supply could be reduced or minimised to zero. The historic data that can be found in the same database, can determine average sunny hours or average sunny days for certain months. That can estimate the heat that can be used from solar radiation.

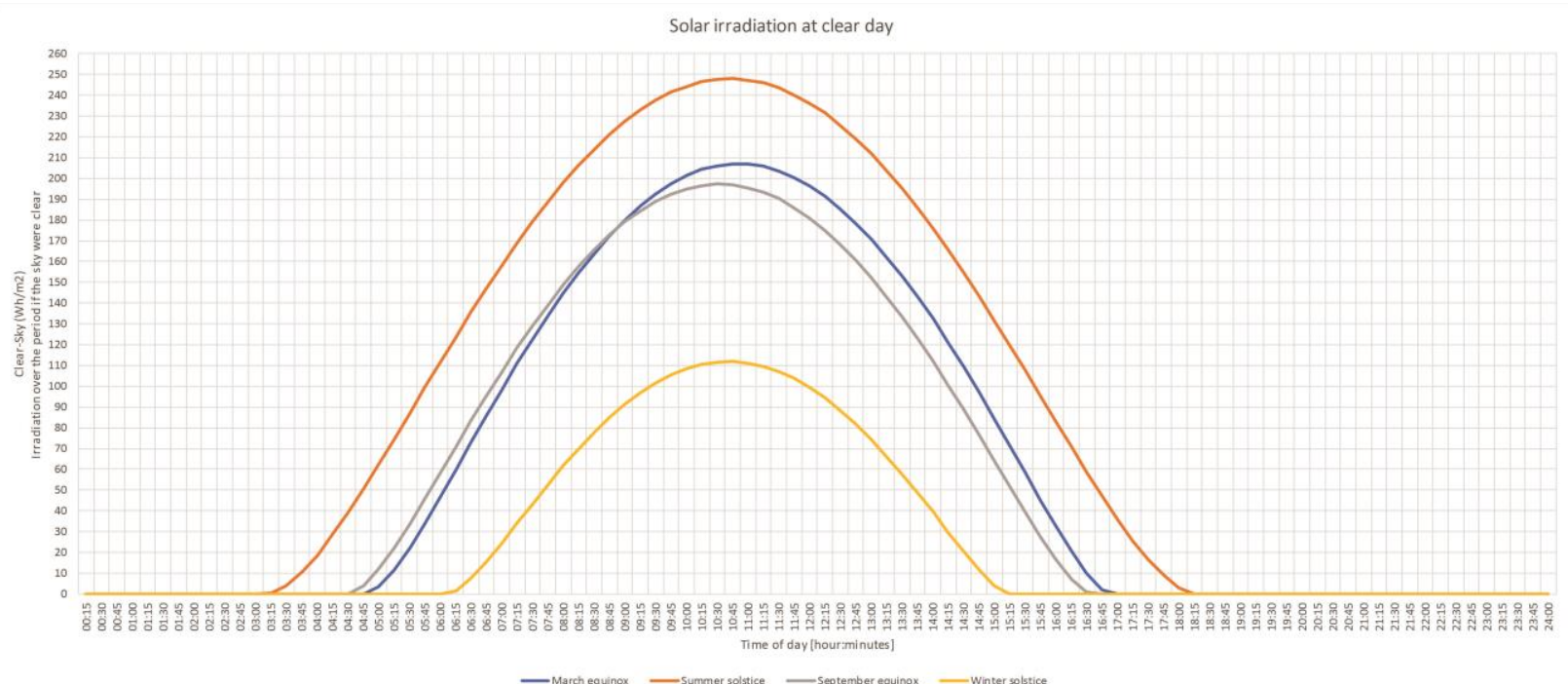

Figure 1. Solar radiation data for the city of Bitola in case of a clear day (the ideal insolation)

\subsection{Proposed methodology}

For solving of given problem was proposed procedures in following steps:

1. Analysis of production plant for independent batches

2. Determination of heat demand, heat flow demand and processing time of batches

3. Extraction of data for solar radiation on daily basis

4.Determination of the shortest processing time as the smallest sequence in the production 
system

5. Sequencing of solar radiation to the smallest sequence of batches in the production system

6. Scheduling of batch sequences in the limited solar heat distribution. (order from the smallest to the highest heat requirement process)

7. Determination of the final scheduling and possibilities for further optimisation inside the schedule

The first three steps are made and explained in the chapters before. Now, the batches given in Table 1 should be reviewed. The shortest processing time that required heat is preheating of CIP during the cleaning process. That is the time of cleaning for each batch. So, the shortest processing time is determined to be 15 minutes. The solar data are differentiated to time periods of 15 minutes (Figure 2). Every 15 minutes have specific solar heat irradiated to the solar heat absorber. The solar heat in Figure 2 is the heat delivered to $1 \mathrm{~m}^{2}$ of heat absorbers. That means, the absorbing area is not enough for any process. So, there must be determined the maximal thermal flow needed to satisfy some of the processes in batches. According to Table 1, sterilisation required the maximal heat flow of 1,277.6 kW. That heat flow must be transferred at maximal solar irradiation, or during the time period of that amount is needed. The time of sterilisation is 0.5 hours. That means at least 30 minutes of the day must have that maximal flux. This procedure is taken for the winter solstice, but the same procedure needs to be done for each day for required batches. At the winter solstice, the maximal solar heat delivered at $1 \mathrm{~m}^{2}$ absorber is approximately $110 \mathrm{Wh} / \mathrm{m}^{2}$. That radiation is emitted between 10:15-11:15. That is one hour. So, during this hour can be done the process of sterilisation. The heat flux at that hour will be $1,277.6 \mathrm{~kW}$ and for other time periods it will be proportionally distributed as it is given on the curve. The ratios can be seen from the Table 2 .

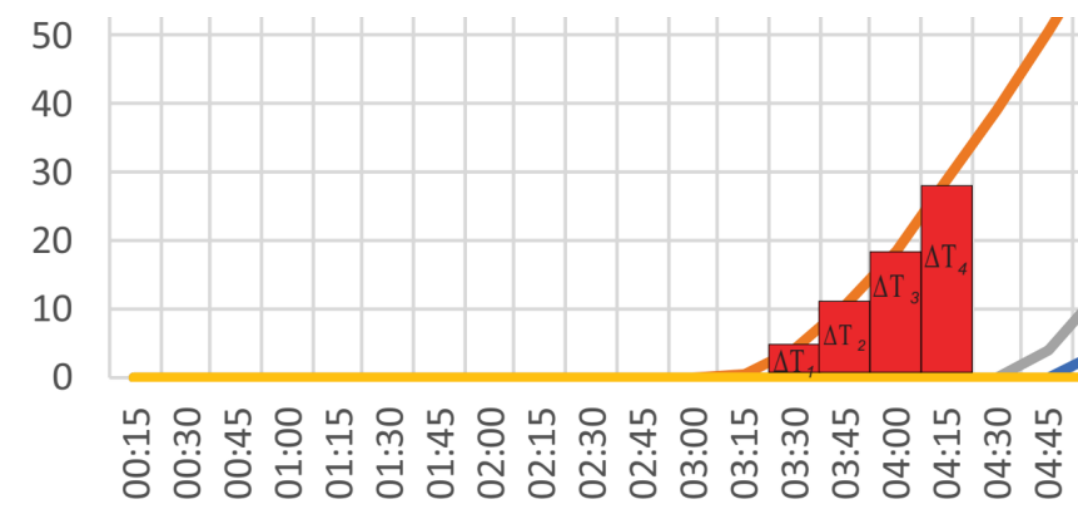

Figure 2. Differentiation of solar heat data into time periods of 15 minutes

Table 2. The solar heat flux with the maximal requirement heat

\begin{tabular}{lrrrrr}
\hline time & ratio & Heat flux $[\mathrm{kW}]$ & \multicolumn{1}{c}{ time } & ratio & Heat flux [kW] \\
\hline $06: 15$ & 0.01 & 18.7 & $10: 45$ & 1.00 & $1,277.6$ \\
$06: 30$ & 0.07 & 86.0 & $11: 00$ & 0.99 & $1,270.0$ \\
$06: 45$ & 0.14 & 176.8 & $11: 15$ & 0.98 & $1,252.1$ \\
$07: 00$ & 0.22 & 279.6 & $11: 30$ & 0.96 & $1,223.8$ \\
$07: 15$ & 0.30 & 387.5 & $11: 45$ & 0.93 & $1,185.5$ \\
$07: 30$ & 0.39 & 496.0 & $12: 00$ & 0.89 & $1,137.4$ \\
\hline
\end{tabular}




\begin{tabular}{rrrrrr}
\hline $07: 45$ & 0.47 & 602.1 & $12: 15$ & 0.84 & $1,079.4$ \\
$08: 00$ & 0.55 & 703.8 & $12: 30$ & 0.79 & $1,011.9$ \\
$08: 15$ & 0.63 & 799.7 & $12: 45$ & 0.73 & 935.8 \\
$08: 30$ & 0.70 & 888.7 & $13: 00$ & 0.67 & 851.6 \\
$08: 45$ & 0.76 & 969.9 & $13: 15$ & 0.59 & 760.0 \\
$09: 00$ & 0.82 & $1,042.8$ & $13: 30$ & 0.52 & 661.9 \\
$09: 15$ & 0.87 & $1,106.4$ & $13: 45$ & 0.44 & 558.3 \\
$09: 30$ & 0.91 & $1,160.0$ & $14: 00$ & 0.35 & 450.7 \\
$09: 45$ & 0.94 & $1,203.9$ & $14: 15$ & 0.27 & 341.0 \\
$10: 00$ & 0.97 & $1,237.8$ & $14: 30$ & 0.18 & 232.4 \\
$10: 15$ & 0.99 & $1,261.4$ & $14: 45$ & 0.10 & 130.2 \\
$10: 30$ & 1.00 & $1,277.0$ & $15: 00$ & 0.04 & 45.1 \\
& & & $15: 15$ & 0.00 & 1.7 \\
\hline
\end{tabular}

\section{Results}

The highest demand for heat has sterilisation. That batch will be scheduled first in the timeline with available solar heat. The sterilisation will start at 10:30 until 11:00. Before sterilisation starts, the system must be cleaned. CIP preheating will start at 10:15 $(145 \mathrm{~kW})$. The heating of CIP liquids needs to start between the beginning of the sunlight and the first CIP cleaning. CIP heating will end at the moment when it gets the right temperature of $95^{\circ} \mathrm{C}$. Before sterilisation $\mathrm{S}$, the solar heat is available with more than $1,173 \mathrm{~kW}$. That means few time periods before sterilisation can be scheduled parallel batches. P1 and P3. P3 can be scheduled between 9:30 and 10:30. The pasteurisation P1 can be placed between 9:45 - 10:15. Before P1 and P3 have cleaning with CIP (preheating). The first time period with available heat for the rest of pasteurisation is before 9:30. P2 has duration of 1.5 hours. So, it can start at 9:45. During that time, there is available solar heat for that process. Since 9:30 - 9:45 is cleaning of the process line for P2. All this available and used solar heat can be seen from Table 3 .

Table 3. Used and available heat from solar heating system without heat storage

\begin{tabular}{|c|c|c|c|c|c|c|c|c|c|c|c|c|c|c|}
\hline & 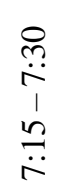 & 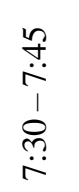 & $\begin{array}{c}\stackrel{8}{8} \\
\dot{\infty} \\
1 \\
n \\
\stackrel{+}{\sim}\end{array}$ & 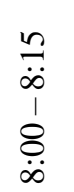 & $\begin{array}{c}0 \\
\dddot{n} \\
\infty \\
1 \\
n \\
\ddot{\infty}\end{array}$ & $\begin{array}{c}\stackrel{8}{0} \\
\dot{a} \\
1 \\
\stackrel{n}{\prime} \\
\dot{\infty}\end{array}$ & $\begin{array}{l}n \\
\ddot{a} \\
1 \\
8 \\
\ddot{a}\end{array}$ & $\begin{array}{l}\stackrel{\rho}{a} \\
\ddot{a} \\
\dot{n} \\
\ddot{a}\end{array}$ & $\begin{array}{l}n \\
\ddot{a} \\
\dot{1} \\
0 \\
\stackrel{n}{0}\end{array}$ & $\begin{array}{c}\stackrel{\rho}{0} \\
\stackrel{0}{0} \\
1 \\
\stackrel{n}{+} \\
\ddot{a}\end{array}$ & $\begin{array}{l}\frac{n}{0} \\
\dot{0} \\
\dot{\rho} \\
\stackrel{0}{0} \\
\dot{0}\end{array}$ & $\begin{array}{l}\stackrel{0}{\dddot{n}} \\
\stackrel{0}{1} \\
\stackrel{1}{n} \\
\ddot{0}\end{array}$ & $\begin{array}{l}\stackrel{n}{+} \\
\stackrel{0}{0} \\
\dot{\rho} \\
\stackrel{?}{0} \\
0\end{array}$ & 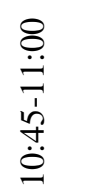 \\
\hline $\mathrm{S}$ & & & & & & & & & & & & & 1277 & 1277 \\
\hline P3 & & & & & & & & & 586 & 586 & 586 & 586 & & \\
\hline $\mathrm{P} 1$ & & & & & & & & & & 586 & 586 & & & \\
\hline $\mathrm{P} 2$ & & & 586 & 586 & 586 & 586 & 586 & 586 & & & & & & \\
\hline CIP & 523 & & & & & & & & & & & & & \\
\hline CIP* & & 145 & & & & & & 145 & 145 & & & 145 & & \\
\hline Used & 523 & 145 & 586 & 586 & 586 & 586 & 586 & 731 & 731 & 1173 & 1173 & 731 & 1277 & 1277 \\
\hline
\end{tabular}




\begin{tabular}{lllllllllllllll}
\hline $\begin{array}{l}\text { heat } \\
\text { Avail } \\
\text {.heat }\end{array}$ & 496 & 602 & 704 & 800 & 888 & 970 & 1042 & 1106 & 1160 & 1204 & 1237 & 1261 & 1277 & 1277 \\
\hline
\end{tabular}

The heating of CIP liquids will start at $6: 15$ until its temperature becomes $95^{\circ} \mathrm{C}$ or to the beginning with the first CIP cleaning at 7:30. The rest of available solar heat can be used for further processes or storing of hot water. The designed schedule can be seen on Figure 3.

The make span of processes is 3.5 hours between 7:30-11:00.

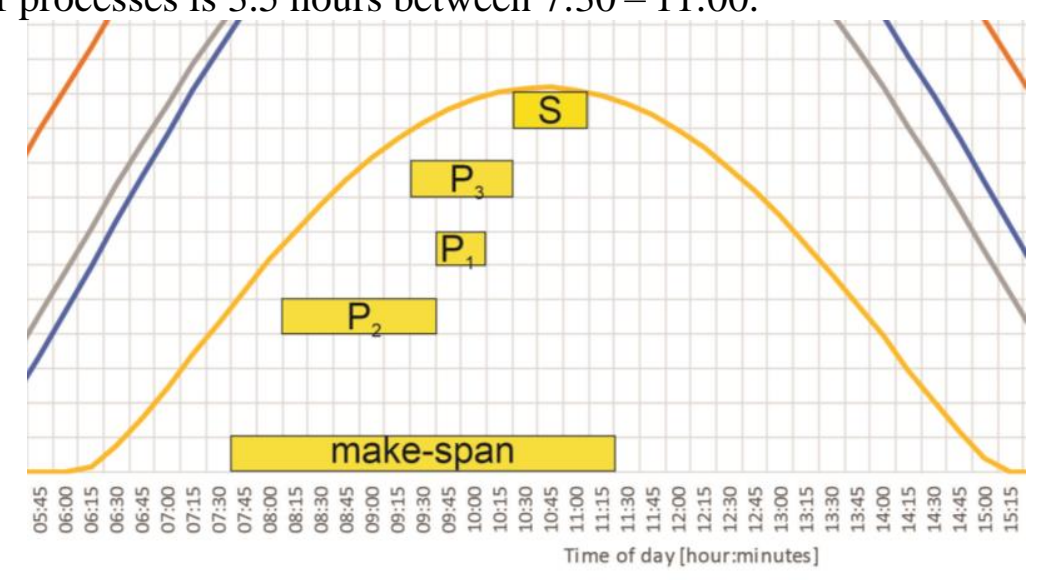

Figure 3. The schedule of batches limited with solar heating supply

\section{Conclusions}

Using of solar heat in production processes that not needed heat storage is a limitation in schedule. In this paper it was shown procedures for preparing schedule of independent batches in independent lines based on current supply of solar heat. It was made for the winter solstice, but the different combinations or the same combination must be rescheduled for every different day. Possibilities for parallel processing of batches make minimisation of the makespan. This procedure of scheduling can be used for appropriate estimation the size of solar heating system. In case of design of solar heating system, there must be taken efficiency of collector system, efficient heat transfer, weather conditions and statistics from historic records about sunny days or sunny hours. The future work can upgrade this procedure with design of solar heating system and its economic analysis, as well as internal heat integration for recipes in determined time slices of the schedule.

\section{References}

[1] Lee J-Y, Seid ER, Majozi T. Heat integration of intermittently available continuous streams in multipurpose batch plants. Computers \& Chemical Engineering 2015;74:100-14.

[2] Costa A. Hybrid genetic optimisation for solving the batch-scheduling problem in a pharmaceutical industry. Computers \& Industrial Engineering 2015;79:130-47.

[3] Samuel Moniz (ed.). SCHEDULING WITH EQUIPMENT REDESIGN IN MULTIPURPOSE BATCH PLANTS; 2012. 
[4] Chao Ning. Batch Process Scheduling under Uncertainty using Data-Driven Multistage Adaptive Robust Optimization. CHEMICAL ENGINEERING TRANSACTIONS 2017;61.

[5] Bettina Muster-Slawitsch. Methodology for Batch Heat Integration and Storage System Design for Ideal Integration of Solar Process Heat.

[6] Mousavi Maleki S, Hizam H, Gomes C. Estimation of Hourly, Daily and Monthly Global Solar Radiation on Inclined Surfaces: Models Re-Visited. Energies 2017;10(1):134.

[7] Seid ER, Majozi T. Heat integration in multipurpose batch plants using a robust scheduling framework. Energy 2014;71:302-20.

[8] Kopanos GM, Puigjaner L. Solving Large-Scale Production Scheduling and Planning in the Process Industries. Cham: Springer International Publishing; 2019.

[9] Baker KR, Trietsch D. Principles of sequencing and scheduling. Hoboken NJ USA: John Wiley \& Sons Inc; 2019.

[10] Majozi T, Seid ERa, Lee J-Y. Understanding Batch Chemical Processes: Modelling and Case Studies / Thokozani Majozi, Esmael R. Seid, Jui-Yuan Lee; 2017.

[11] Majozi T, Seid ER, Lee J-Y. Synthesis, design, and resource optimisation in batch chemical plants. 1st ed. Boca Raton: CRC Press; 2015.

[12] HelioClim-3 Archives for Free-www.soda-pro.com. [July 22, 2019]; Available from: http://www.soda-pro.com/web-services/radiation/helioclim-3-archives-for-free. 